\title{
Variability in Compensatory Ability and Relative Invasive Potential in Ornamental Cleomes
}

\author{
Nadilia N. Gómez Raboteaux ${ }^{1} \&$ Neil O. Anderson ${ }^{2}$ \\ ${ }^{1}$ Research Analyst - RIM, Pioneer Hi-Bred Seed Co., Johnston, IA, USA \\ ${ }^{2}$ Department of Horticultural Science, University of Minnesota, Saint Paul, MN, USA \\ Correspondence: Neil O. Anderson, 305 Alderman Hall, 1970 Folwell Avenue, Saint Paul, MN 55106, USA. \\ E-mail: ander044@umn.edu
}

Received: May 16, 2014 Accepted: June 26, 2014 Online Published: June 28, 2014

doi:10.5539/ijb.v6n4p1 URL: http://dx.doi.org/10.5539/ijb.v6n4p1

\begin{abstract}
Tolerance to herbivory is an important trait influencing invasive potential of exotic plant species. However, though many invasive plant species have been introduced as ornamentals, tolerance to herbivory has not been evaluated among cultivars of ornamental crops to assess relative invasive potential. A greenhouse study was performed to compare tolerance to simulated herbivory in five Cleome cultivars (Sparkler White, Sparkler Rose, Queen White, Queen Rose and Solo). The herbivory treatments simulated deer, rabbit and invertebrate herbivore damage by clipping the main stem, removing leaves, or punching out leaf pieces, respectively. Data were collected for flowering time, vegetative and reproductive biomass, ratio of reproductive: vegetative biomass (reproductive effort), number of flowering and vegetative shoots, ratio of number of flowering: total shoots (reproductive allocation), and number of ovules/flower. Cultivars showed different norms of tolerance ranging from under compensation to overcompensation with differences among cultivars within series. The response differed among patterns of simulated herbivory with stem clipping having the most dramatic and negative effect on plant growth and reproduction relative to whole leaf and partial leaf defoliation. The response also varied depending on cultivar and trait. For example, compensation in vegetative, but not reproductive, biomass, was observed across most cultivars after clipping. Significant interactions of herbivory treatment $\mathrm{x}$ cultivar were detected for total shoot number and the ratio of flowering: total shoots in the stem clipping experiment, indicating shifts in relative cultivar ranks. The implication of variation in tolerance to herbivory is discussed in relation to ornamental crop development and invasive species risk assessment.
\end{abstract}

Keywords: biomass allocation, Cleome hassleriana, Cleome serrulata, plant-herbivore interactions, Polanisia dodecandra, simulated herbivory

\section{Introduction}

Plant-herbivore interactions play a significant role in determining whether an exotic species becomes invasive (Bigger \& Marvier, 1998; Crawley, 1989). When an exotic species is introduced to a new region, a shift in the composition of herbivore is likely. The exotic species may be released from the herbivores present in its native range and possibly exposed to a different set of herbivores in the area of introduction. Therefore, response to different patterns of herbivory is likely to affect the probability of population establishment and growth.

Several hypotheses on plant-herbivore interactions have been proposed to explain rapid population growth in invasive species. On one hand, the enemy release hypothesis (ERH) proposes that population size of exotic species will increase because they are no longer constrained by the herbivores in their native range which would normally limit population size expansion (Keane \& Crawley, 2002). In contrast, herbivores may increase population size if they have a positive effect on plant fitness. This idea has been explored as the grazing optimization hypothesis $(\mathrm{GOH})$, which suggests that plant productivity can increase with moderate levels of herbivory (de Mazancourt, Loreau, \& Dieckmann, 2001). Another hypothesis, the evolution of improved competitive ability (EICA), suggests that invasive species have increased fitness because resources are reallocated from defense to growth and reproduction in response to reduced herbivory (Blossey \& Nötzold, 1995; Joshi \& Vrieling, 2005).

Whereas resistance through plant defense compounds acts primarily to deter specialist herbivores, tolerance enables a species to sustain herbivore damage from a broad range of herbivores (Müller-Schärer, Schaffner, \& Steinger, 2004). Selection for tolerance to herbivory by means of an increase in leaf size, branching or tillering, 
increased growth rates and net photosynthetic rate, activation of dormant meristems, and changes in plant architecture and allocation patterns in response to herbivory (Strauss \& Agrawal, 1999; van Kleunen \& Schmid, 2003; Bossdorf, Schröder, Prati, \& Harald, 2004) is expected to be an important evolutionary change leading to increased survival and establishment of exotic species. The degree to which plants tolerate herbivory is known as compensatory ability or compensation (Strauss \& Agrawal, 1999).

Compensatory ability can be of value in estimating the relative invasive potential of ornamental cultivars before crops are commercially distributed (Belsky, 1986; Hochwender, Marquis, \& Stowe, 2000). Many exotic species that have become invasive have been introduced as ornamentals (Reichard \& White, 2001). Despite a lack of protocols to evaluate invasive potential during crop development and prior to market release of a new crop (Anderson \& Gomez, 2004), cultivars are being advertised as less invasive than others based solely on performance in traditional breeder trials. Such trials are primarily designed to evaluate the suitability of cultivars to production regimes and, though they might provide information about life history traits, they are very limited in their ability to predict a crop's response to herbivores.

Breeder trials cannot provide information about response to herbivory because plants are routinely evaluated in cultivated habitats where herbivores are excluded. For example, Cleome hassleriana and Polanisia dodecandra (sold as C. serrulata) are annuals of the Capparaceae present in Northeastern US (Gleason \& Cronquist, 1991) that are bred for ornamental purposes. Cleome hassleriana is native to southeastern Brazil and Argentina (Still, 1994), is commonly used as a garden ornamental plant and a cut flower (Nau, 1999), reseeds prolifically and has occasionally escaped from cultivation (Bailey, 1927; Kindscher, 1987; Gleason \& Cronquist, 1991). Polanisia dodecandra is native to North America (Kindscher, 1987; Gleason \& Cronquist, 1991). It grows in open prairies, sandy and rocky soils, open woodlands and disturbed sites (Whitson, 1991; Freeman, 1991). Polanisia dodecandra is distasteful to animals (Steffey, 1984). It produces glucosinolates that act as repellents against most herbivores, except those that have evolved tolerance to mustard-oils (Cronquist, 1988). Cleome hassleriana has spines along stems, petioles, and leaf mid-veins that provide mature plants with additional protection against herbivores. In non-cultivated habitats, however, mammals and invertebrates can cause removal of apical meristems, various degrees of defoliation, and seedling death despite these mechanisms that deter herbivores. In a preliminary study of growth and establishment of cleome cultivars in non-cultivated habitats significant mortality was observed in transplanted seedlings due to herbivory in prairies (94\%) and roadside (76\%) conditions but not in garden conditions (10\%) (Gomez, unpublished data). This suggests that when cleomes are grown in gardens, they are rarely attacked by herbivores, but when grown in non-cultivated settings, herbivore damage, especially on seedlings, can dramatically reduce survival probabilities.

'Solo', on the other hand, is the product of a more recent domestication event. Its resemblance to the wild species Polanisia dodecandra suggests that the development of this cultivar is best described as a bottleneck of the indigenous species rather than a prolonged and intense selection for ornamental characteristics. Compensatory ability in Cleome cultivars is likely to contribute to invasive potential in non-cultivated environments. This study, using three types of herbivory experiments, aimed: (1) to determine whether Cleome cultivars exhibit tolerance to various patterns of simulated herbivory, (2) to compare the growth and reproduction response among Cleome cultivars in different patterns of herbivory, and (3) to determine the extent to which cultivars differ in their response to simulated herbivory. To our knowledge, this is the first study to compare tolerance to simulated herbivory among ornamental cultivars prior to naturalization in the context of assessing relative invasive potential.

\section{Method}

\subsection{Study Species}

Cultivars advertised as good alternatives for the more aggressive 'Queen' include 'Sparklers' and 'Solo'. The pedigree leading to the development and selection of Sparklers is proprietary information (T. Perkins, Goldsmith Seed Co., personal communication), but it is likely that they are derived from dwarf Cleome mutants, possibly a gibberellic acid (GA) mutant. In addition to their shorter stature relative to Queens, Sparklers have a greater percent of non-viable seeds than Queens. 'Solo' is advertised as a 'native' alternative to Queen. Despite its smaller flowers and unpleasant odor which make it less appealing as a garden plant (Whitson, 1991), 'Solo' is becoming more popular as more plant enthusiasts search for native annuals to incorporate into their gardens (Lee, 2000).

Four C. hassleriana cultivars ('Queen Rose' $=\mathrm{QR}$, 'Queen White' $=\mathrm{QW}$, 'Sparkler Rose' $=\mathrm{SR}$, 'Sparkler White'=SW) and one $P$. dodecandra cultivar ('Solo'=S) were evaluated in this study (Table 1). Among the five cultivars studied are those that have naturalized outside cultivation and those that have been advertised as less aggressive alternatives. 'Queen' series cultivars have been marketed as ornamentals for almost a century as documented by references dating back to as early as 1912 in the Curtis' Botanical Magazine of London, the oldest 
current periodical devoted to garden plants (Bailey, 1927). Populations of 'Queen Pink' have been documented in the eastern half of the United States extending from as far west as Texas and ranging as far north into the upper Peninsula of Michigan (USDA Plants Database, 2005). Since colored flowers are most likely of dominant inheritance in cleomes, it is not possible to rule out the role of 'Queen White' in the origin of naturalized populations even though naturalized plants exhibit primarily, pink-colored flowers.

Table 1. Cleome cultivars and sources evaluated for tolerance to three different patterns of simulated herbivory (stem clipping, whole leaf defoliation, partial leaf defoliation) in greenhouse conditions

\begin{tabular}{lllll}
\hline Cultivar & Abbreviation & Series $^{\mathrm{a}}$ & Cleome spp. & Company \\
\hline Solo & $\mathrm{S}$ & none $^{\mathrm{b}}$ & C. serrulata $^{\mathrm{c}}$ & Express Seeds \\
Sparkler Rose & SR & Sparkler & C. hassleriana & Ball Seed Co., Inc \\
Sparkler White & SW & Sparkler & C. hassleriana & Ball Seed Co., Inc \\
Queen Rose & QR & Queen & C. hassleriana & Ball Seed Co., Inc \\
Queen White & QW & Queen & C. hassleriana & Ball Seed Co., Inc
\end{tabular}

${ }^{a}$ A series is a group of cultivars that share most phenotypic traits of ornamental value but differ in flower color.

b 'Solo' is not grouped within a series because it is available only in one flower color.

${ }^{\mathrm{c}}$ C. serrulata is the name under which this cultivar is being sold, even though based on anther number and viscid pubescence it is Polanisia dodecandra.

Seeds used in this study were purchased from Express Seed Co. (Oberlin, OH USA) and Ball Seed, Co. (West Chicago, IL USA). Seeds were sown on June 26, 2003 in the greenhouses of the University of Minnesota, St.

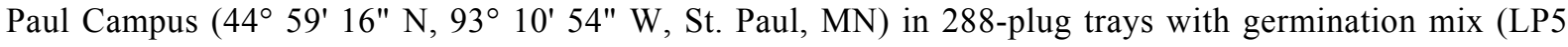
Germination Mix, Sun Gro Horticulture Sunshine, Pine Bluff, AR) and loosely covered with vermiculite (Medium Vermiculite Premium Grade, Sun Gro Horticulture Sunshine, Pine Bluff, AR). Trays were taken that same day to Wagner Greenhouses ( $44^{\circ} 53^{\prime} 37^{\prime \prime} \mathrm{N}, 93^{\circ} 18^{\prime} 30^{\prime \prime} \mathrm{W}$, Minneapolis, MN) where seeds were germinated on greenhouse benches at approximately $26^{\circ} \mathrm{C}$ day $/ 21^{\circ} \mathrm{C}$ night temperatures (Ball, 1965; Nau, 1999). Two weeks later, trays were brought back to the St. Paul Campus and placed in the greenhouses until August 18 when they were transplanted into $15.24 \mathrm{~cm}(6 \mathrm{inch})$ plastic pots filled with potting medium (SB300 Universal Professional Growing Mix, Sun Gro Horticulture Sunshine, Pine Bluff, AR). Plants were grown in the greenhouses of the University of Minnesota, St. Paul Campus for a month before being randomly assigned to one of the three simulated herbivory experiments described below.

\subsection{Experimental Design}

Three experiments differing in the pattern of simulated-herbivore damage were conducted, each of which were designed to answer the three aims of this paper (see above): (1) stem clipping simulated deer browsing by removing half of the main stem on treated plants including the apical and several lateral meristems; (2) whole leaf defoliation simulated rabbit herbivory by removing either all the main leaves or both main and axillary leaves at the base of the leaf blade where the leaf joins the petiole; (3) partial leaf defoliation simulates the effect of folivores that remove small portions of the leaf blade throughout the entire plant though allow damaged leaves to remain attached to the plant. Before initiating the experiments, the height of ten randomly selected plants from each cultivar population was recorded as an initial gauge of plant height differences and variation within and among cultivars.

Twenty plants of each cultivar were randomly selected for the stem clipping experiment. The distal half of the main stem was clipped off (Hester, Millard, Bailllie, \& Wendler, 2004; Bergquist, Bergstrom, \& Zakharenka, 2003) in ten randomly selected plants from each cultivar (reps). The remaining plants were untreated (control). All plants were set on a single bench in the greenhouse in a completely randomized design.

For the whole leaf defoliation experiment, twelve plants of each cultivar were randomly chosen. Four plants from each cultivar (reps) were randomly assigned to one of three treatments consisting of complete removal of all leaves from main and axillary shoots, removal of mature leaves on the main stem only, and a control treatment with no leaf removal. Leaves were removed by cutting off the petiole at the base of the leaf (Markkola, Kuikka, Rautio, Härmä, Roitto, \& Tuomi, 2004). Plants were treated and distributed in a complete randomized block design across three greenhouse benches (blocks). 
For the partial leaf defoliation experiment, four plants per cultivar (reps) were randomly assigned to each treatment level of leaf removal: low (L), 20\% total leaf area; intermediate (I), 40\% total leaf area in QR, QW and SR, 50\% total leaf area in SW; and high $(\mathrm{H}), 80 \%$ total leaf area and one of three greenhouse benches (blocks) in a completely randomized block design. A calibrated leaf area meter was used to determine total leaf area in two plants per cultivar. Holes were punched using a 1/8" circular steel, paper punch to simulate three herbivory intensities. The number of holes punched per plant was determined for each cultivar based on the desired level of damage (L, I, H, control) and the average total leaf area per cultivar. Holes were haphazardly distributed on the leaf and plant, meaning that the holes were distributed throughout the plant avoiding damage to the leaf mid vein (Rogers \& Siemann, 2003) and, in general, smaller leaves had fewer holes applied than larger leaves. 'Solo' was excluded from this experiment because leaflets were too small to be treated without being damaged completely.

Plants from all three experiments were grown simultaneously in the greenhouse under supplemental lighting (400 W high pressure sodium, high intensity discharge lamps, $\sim 100-150 \mu \mathrm{mol}^{-2} \mathrm{sec}^{-1}, 0600-2200 \mathrm{HR}$ ) and fertilized weekly with a 20-20-20 N:P:K soluble fertilizer at $300 \mathrm{ppm} \mathrm{N}$. One month after treatment, flowering phenology was scored for all plants. The scores ranged from 0 to $4(0=$ absence of flower structures of any kind, $1=$ only flower buds present on plant, $2=$ one or three open flowers present on plant, $3=$ more than three open flowers, sometimes with more than one inflorescence with buds and a few open flowers, $4=$ plants in full bloom, with more than one flowering inflorescences, sometimes with senescing flowers or seed pods).

Experiments were terminated 40 days after treatment. Axillary shoots were counted and recorded as flowering or non-flowering (flowering phenology). Inflorescences and vegetative tissues were separated, placed into paper bags, and dried in the oven at $75^{\circ} \mathrm{C}$ for at least four days until dry weights stabilized to obtain relative dry weights of reproductive and non-reproductive (vegetative) plant parts. Other traits measured, though not discussed in this paper, included number and length of axillary shoots, number of leaves, and two measurements of total height 1 month apart to estimate growth rate.

Before drying reproductive tissues, at least one, $1-\mathrm{cm}$ long, ovary was harvested from every flowering plant and fixed in Farmer's solution (95\% ethanol : glacial acetic acid solution, 3:1 v/v) (Chamberlain, 1932). This length was chosen because preliminary ovary dissections showed that ovules were well-developed and could be counted readily at this stage. Ovaries were transferred into $70 \%$ ethanol one week later and then into vials containing distilled, de-ionized water and stored in the lab, until they could be dissected. Gynoecia were measured from the base of the ovary to the tip of the stigma. They were dissected under a dissecting microscope, ovules were counted, and morphological abnormalities of the ovaries were recorded. The number of ovules per ovary was measured as a measure of reproductive output. It was not determined if the ovaries counted at this stage of development have been fertilized or not.

\subsection{Statistical Analyses}

Most traits were analyzed using Statistical Package for the Social Sciences (SPSS) version 11.0 unrestricted, univariate, fixed-effects, general linear model (SPSS Inc., 2001) with main factors and all possible interactions included in the model. Flowering phenology was analyzed using a two-way ANOVA and interaction by standard least squares (JMP IN 1989-2000). Post-hoc tests of Least Significant Difference (LSD) at $\alpha=0.05$ were performed on initial plant heights. To determine differences among cultivars within the series of the same species, 'Solo' was dropped from the analysis and a model with cultivars nested within series was used. Ovary length was used as a covariate in the analysis of ovule counts because it differed across cultivars. Significant differences in the proportion of ovary abnormalities across treatments and cultivars were determined using a Likelihood Ratio test.

Prior to analysis, the data were tested for normality, heteroscedasticity, and outliers. Vegetative and reproductive biomasses in the stem clipping and whole leaf defoliation experiments were square-root transformed. Reciprocal square root transformations were used for total shoot number in all three experiments and flower shoot number in the stem clipping experiment. For number of total shoots, four outliers were removed from the whole leaf defoliation data. For the analyses of biomass, one outlier was removed from the whole leaf defoliation data. One outlier was dropped from the partial leaf defoliation data for the number of branches and four from the whole leaf defoliation data. This did not affect the overall outcome of the results. Back-transformed means and standard errors were used to make the graphs in the original scale, whenever a transformation was required for the analyses.

\section{Results}

Height of cultivars before treatment ranged from $12.7 \mathrm{~cm}$ in SR to $20.4 \mathrm{~cm}$ in QW (Figure 1). The average height for QW and QR plants before herbivory treatment was 20.4 and $18.1 \mathrm{~cm}$, respectively. QW and QR plants were significantly taller than SR $(12.7 \mathrm{~cm})$, SW $(14.5 \mathrm{~cm})$, and $\mathrm{S}(13.2 \mathrm{~cm})$ plants. Variation in height among individuals within cultivars (low S.E., Figure 1) was minor, however. Height before treatment might have had a residual effect on the response to simulated herbivory. However, size alone does not explain the differences in 
tolerance to herbivory since, as will be discussed below, differences among cultivars in tolerance to herbivory were not always consistent with initial plant height.

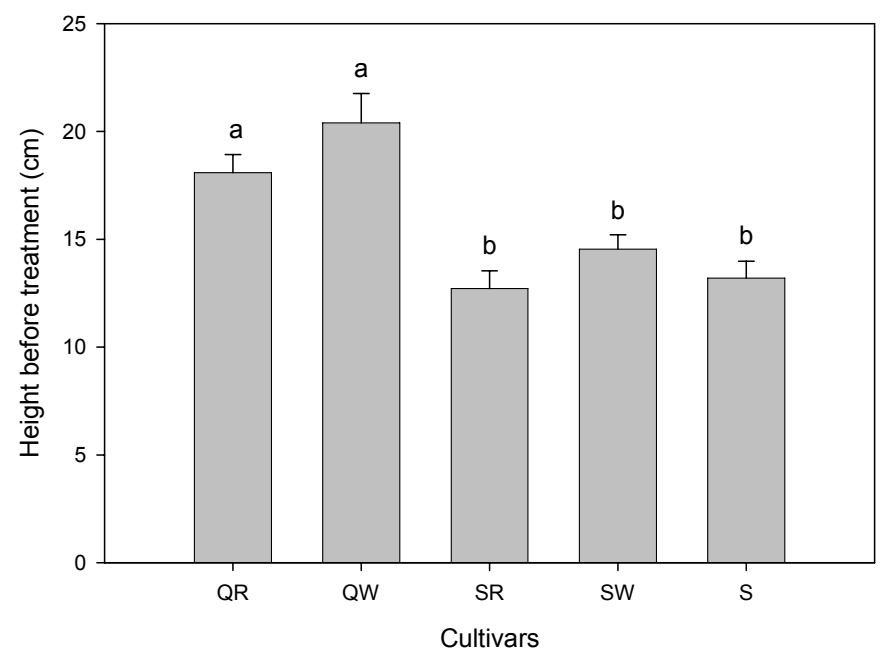

Figure 1. Mean $( \pm$ S.E. $)$ height $(\mathrm{cm})$ of Cleome hassleriana and Polanisia dodecandra cultivars before simulated herbivory treatments. Height was measured on $\mathrm{n}=10$ randomly selected plants from each cultivar of

C. hassleriana (QW = 'Queen White'; $\mathrm{QR}=$ 'Queen Rose'; SW = 'Sparkler White'; SR = 'Sparkler Rose'), and P. dodecandra $(\mathrm{S}=$ 'Solo'). Letters indicate groups with similar means according to Least Significant Difference post-hoc test at $\alpha=0.05$ level

\subsection{Flowering Phenology}

Stem clipping reduced the initial time to flowering in all cultivars (Figure 2). Herbivory treatment and cultivar had significant effects on flowering phenology (Table 2). Stem clipping reduced the average flowering phenology score to 0.8 , compared to an average score of 2.4 in control plants. Among all cultivars, $\mathrm{S}$ had the lowest average score (0.6), suggesting a longer time to flowering. The difference in average scores between Sparkler cultivars (0.9) was greater than the difference between Queen cultivars $(0.1)$ suggesting greater variation in time to flowering in Sparklers than in Queens.

Table 2. Significance ( $P$ values) from the two-way Analysis of Variance for flowering phenology in five Cleome cultivars (Queen Rose, Queen White, Sparkler Rose, Sparkler White, and Solo) in response to three simulated herbivory experiments (stem clipping, whole leaf defoliation, partial leaf defoliation)

\begin{tabular}{|c|c|c|c|}
\hline Simulated herbivory & Factor $^{\mathrm{a}}$ & $\mathrm{df}$ & $P$ values ${ }^{\mathrm{b}}$ \\
\hline \multirow[t]{3}{*}{ Stem clipping } & $\mathrm{cV}$ & 4 & $<0.001 * * *$ \\
\hline & $\operatorname{trt}$ & 1 & $<0.001 * * *$ \\
\hline & $\mathrm{cv} \times \operatorname{trt}$ & 4 & $0.045 *$ \\
\hline \multirow[t]{4}{*}{ Whole leaf defoliation } & $\mathrm{cv}$ & 4 & $<0.001 * * *$ \\
\hline & $\operatorname{trt}$ & 2 & $<0.001 * * *$ \\
\hline & blk & 2 & $0.111 \mathrm{~ns}$ \\
\hline & $\mathrm{cv} \times \operatorname{trt}$ & 8 & $0.101 \mathrm{~ns}$ \\
\hline \multirow[t]{4}{*}{ Partial leaf defoliation } & $\mathrm{cv}$ & 4 & $<0.001 * * *$ \\
\hline & $\operatorname{trt}$ & 3 & $0.855 \mathrm{~ns}$ \\
\hline & blk & 2 & $0.698 \mathrm{~ns}$ \\
\hline & $\mathrm{cv} \times \operatorname{trt}$ & 12 & $0.952 \mathrm{~ns}$ \\
\hline
\end{tabular}

${ }^{\mathrm{a}} \mathrm{cv}=$ cultivar, trt $=$ treatment, $\mathrm{blk}=$ block.

$\mathrm{b} *, * * *, \mathrm{~ns}=$ significant, highly significant, and not significant to $\alpha=0.05$. 


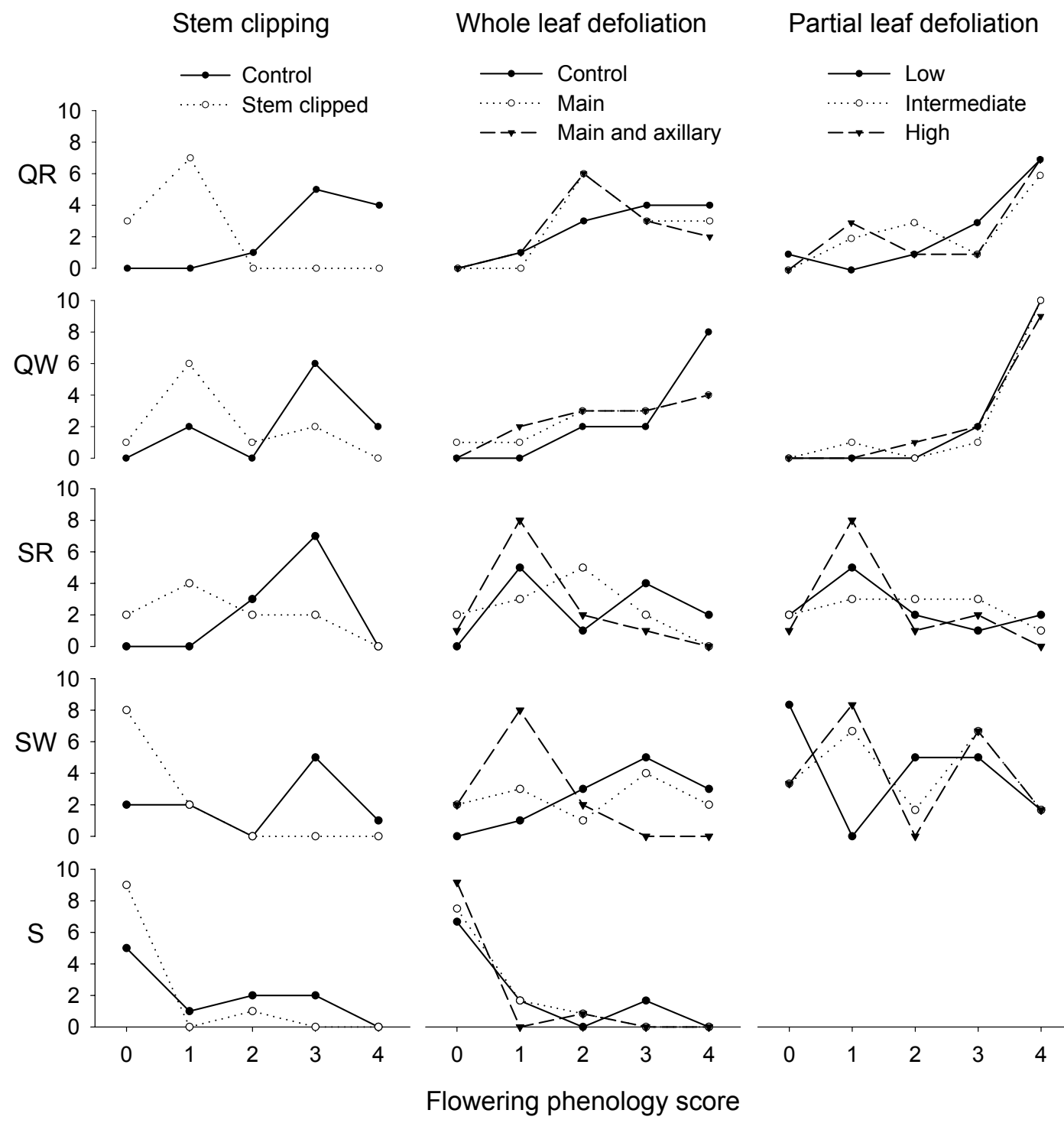

Figure 2. Frequency distribution of Cleome cultivars scored by flowering phenology (0-4 scores; see text). Ten plants per cultivar were scored in the stem clipping experiment, twelve in the whole and partial leaf defoliation experiments. Cultivars: QR = 'Queen Rose', QW = 'Queen White', SR = 'Sparkler Rose', SW = 'Sparkler White', S $=$ 'Solo'. S was excluded from partial leaf defoliation experiment (see text)

There was also a significant interaction between cultivar and stem clipping treatment in flowering phenology score (Table 2). QR control plants scored the highest flowering phenology score, but were only the third highest among treated plants (Figure 3). QW and SR control plants scored similarly and responded equally to the stem clipping treatment, with an average reduction in flowering phenology score of 1.4. Moreover, though $\mathrm{S}$ was most delayed to initiate flowering (scoring the lowest flowering phenology scores), after treatment SW flowering was delayed equally when compared to $\mathrm{S}$ treated plants.

In the whole leaf defoliation experiment, cultivar and treatment had significant effects on time to flowering, but no significant effect of the interaction of cultivar and treatment was detected (Table 2). Queen cultivars had the highest scores for flowering phenology, meaning they initiated flowers the fastest (Figure 3). The cultivar S was the most delayed in flowering with the lowest score for flowering phenology (0.4). In regards to the response to simulated herbivory, time to flowering was delayed as the intensity of damage increased. From control to complete removal of main and axillary leaves, there was a $17.4 \%$ drop in the mean flowering phenology scores. 
In the partial leaf defoliation experiment, time to flowering was significantly affected by cultivar but, despite the intensity of the simulated herbivory damage, no treatment effects were detected (Table 2). Nonetheless, least mean scores in flowering phenology scores were still greater in Queens than in Sparklers (Figure 3).

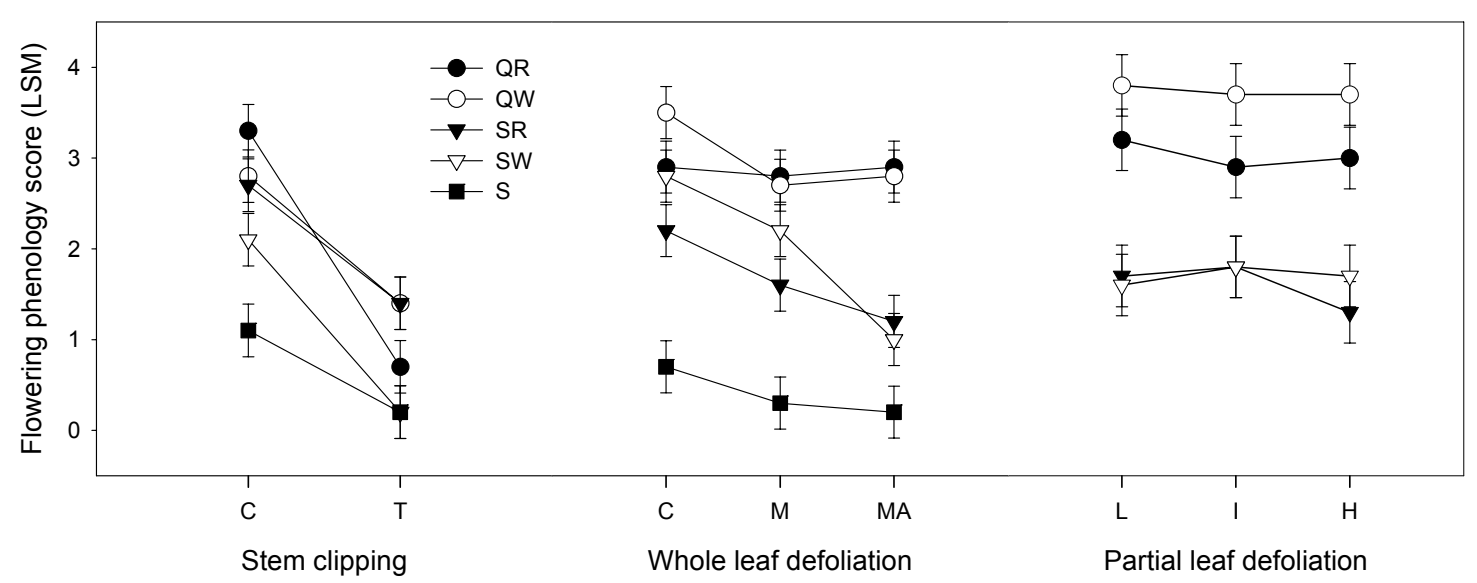

Figure 3. Least square mean plots ( \pm S.E.) of flowering phenology scores of five Cleome cultivars $(\mathrm{QR}=$ Queen Rose, $\mathrm{QW}=$ Queen White, $\mathrm{SR}=$ Sparkler Rose, $\mathrm{SW}=$ Sparkler White, $\mathrm{S}=$ Solo $) 30$ days after stem clipping $(\mathrm{C}=$ control, $\mathrm{T}=$ treated; $\mathrm{n}=10)$, whole leaf defoliation $(\mathrm{C}=$ control, $\mathrm{M}=$ main leaves removed,

$\mathrm{MA}=$ main and axillary leaves removed $)$ and partial leaf defoliation $(\mathrm{L}=$ low, $\mathrm{I}=$ intermediate, $\mathrm{H}=$ high levels of leaf area removed) simulated herbivory experiments

\subsection{Biomass}

In the stem clipping experiment, mean total biomass/plant was reduced from $19.7 \mathrm{~g}$ (control) to $14.3 \mathrm{~g}$ (treated). Since the herbivory simulation consisted of removing half of the plant, it would be expected that total biomass in treated plants would equal $50 \%$ of the total biomass of control plants. In this experiment, however, treated plants averaged $72.5 \%$, instead of $50 \%$, total biomass of control plants. Total biomass in treated plants ranged from $1.4 \mathrm{~g}$ in $\mathrm{S}$ to $21.3 \mathrm{~g}$ in QW. In control plants, it ranged from 6.9 in S to 27.2 in QR. All treated cultivars, except $\mathrm{S}$, produced $>50 \%$ total biomass of control plants. SW $(80.9 \%)$ and QW $(79.0 \%)$ produced the largest percent of total biomass relative to control plants, followed by SR $(69.0 \%)$. On the other hand, S did not compensate after herbivory; the biomass of treated plants was only $20.8 \%$ of control plants.

Stem clipping significantly reduced average vegetative and reproductive biomass per plant (Table 3 ). Vegetative (Figure 4A) and reproductive (Figure 4B) biomass was, on average, less in treated plants than in control plants. Vegetative biomass averaged $15.2 \mathrm{~g}$ for control and $13.0 \mathrm{~g}$ for treated, whereas reproductive biomass was $4.4 \mathrm{~g}$ (control) and $1.3 \mathrm{~g}$ (treated). The greatest difference in vegetative biomass was observed in $\mathrm{S}$ with $4.8 \mathrm{~g}$ more (control) than in treated plants (Figure 4A). Interestingly, this cultivar had one of the smallest differences in biomass of inflorescence between control and treated plants, only $0.65 \mathrm{~g}$ more in control plants than in treated plants (Figure 4B). The greatest difference in reproductive biomass in treated and control plants was observed in QR $(5.8 \mathrm{~g})$, which had the smallest difference in vegetative biomass $(0.8 \mathrm{~g})$. This indicates that the effect of herbivory may be stronger in different traits depending on the cultivar. After simulated herbivory, growth is affected most dramatically in $\mathrm{S}$, while reproduction is most affected in $\mathrm{QR}$. 
Table 3. Significance ( $P$ values) from the univariate, unrestricted, general linear model analyses for biomass and shoot number of five Cleome cultivars (Queen Rose, Queen White, Sparkler Rose, Sparkler White, and Solo) in response to three simulated herbivory experiments (stem clipping, whole leaf defoliation, partial leaf defoliation).

\begin{tabular}{|c|c|c|c|c|c|c|c|c|}
\hline \multirow{2}{*}{$\begin{array}{l}\text { Simulated } \\
\text { Herbivory }\end{array}$} & \multirow[b]{2}{*}{ Factor $^{\mathrm{a}}$} & \multirow[b]{2}{*}{ df } & \multicolumn{3}{|c|}{ Biomass $^{b}$} & \multicolumn{3}{|c|}{ Shoot number ${ }^{\mathrm{c}}$} \\
\hline & & & Veg $^{\mathrm{d}}$ & Rep & Rep:Tot & Tot & Flow & Flow:Tot \\
\hline Stem & $\mathrm{cv}$ & 4 & $<0.001 * * *$ & $<0.001 * * *$ & $<0.001 * * *$ & $<0.001 * * *$ & $0.205 \mathrm{~ns}$ & $0.012 *$ \\
\hline \multirow[t]{2}{*}{ clipping } & $\operatorname{trt}$ & 1 & $<0.001 * * *$ & $<0.001 * * *$ & $<0.001 * * *$ & $<0.001 * * *$ & $<0.001 * * *$ & $0.010^{*}$ \\
\hline & $\mathrm{cv} \times \mathrm{trt}$ & 4 & $<0.001 * * *$ & $0.063 \mathrm{~ns}$ & $0.084 \mathrm{~ns}$ & $<0.001 * * *$ & $0.457 \mathrm{~ns}$ & $0.009 * * *$ \\
\hline Whole & $\mathrm{cv}$ & 4 & $<0.001 * * *$ & $<0.001^{* * *}$ & $<0.001 * * *$ & $<0.001 * * *$ & $<0.001 * * *$ & $0.001 * * *$ \\
\hline leaf & trt & 4 & $<0.001 * * *$ & $<0.001 * * *$ & $0.120 \mathrm{~ns}$ & $0.900 \mathrm{~ns}$ & $0.002 * * *$ & $0.011^{*}$ \\
\hline \multirow[t]{5}{*}{ defoliation } & blk & 2 & $0.001 * * *$ & $0.073 \mathrm{~ns}$ & $0.987 \mathrm{~ns}$ & $<0.001 * * *$ & $0.003 * * *$ & $<0.001 * * *$ \\
\hline & $\mathrm{cv} \times \operatorname{trt}$ & 2 & $0.354 \mathrm{~ns}$ & $0.248 \mathrm{~ns}$ & $0.248 \mathrm{~ns}$ & $0.040^{*}$ & $0.621 \mathrm{~ns}$ & $0.221 \mathrm{~ns}$ \\
\hline & cv x blk & 8 & $0.312 \mathrm{~ns}$ & $0.021 * *$ & $0.03 * *$ & $0.226 \mathrm{~ns}$ & $0.581 \mathrm{~ns}$ & $0.784 \mathrm{~ns}$ \\
\hline & trt $\mathrm{x}$ blk & 4 & $0.297 \mathrm{~ns}$ & $0.339 \mathrm{~ns}$ & $0.666 \mathrm{~ns}$ & $0.046^{* *}$ & $0.111 \mathrm{~ns}$ & $0.113 \mathrm{~ns}$ \\
\hline & cv $x$ trt $x$ blk & 16 & $0.935 \mathrm{~ns}$ & $0.622 \mathrm{~ns}$ & $0.237 \mathrm{~ns}$ & $0.262 \mathrm{~ns}$ & $0.448 \mathrm{~ns}$ & $0.685 \mathrm{~ns}$ \\
\hline Partial & $\mathrm{cv}$ & 4 & $<0.001 * * *$ & $<0.001 * * *$ & $<0.001 * * *$ & $<0.001 * * *$ & $0.177 \mathrm{~ns}$ & $0.01 *$ \\
\hline leaf & trt & 3 & $0.113 \mathrm{~ns}$ & $0.386 \mathrm{~ns}$ & $0.102 \mathrm{~ns}$ & $0.856 \mathrm{~ns}$ & $0.244 \mathrm{~ns}$ & $0.636 \mathrm{~ns}$ \\
\hline \multirow[t]{5}{*}{ defoliation } & blk & 2 & $0.004 * * *$ & $0.855 \mathrm{~ns}$ & $0.160 \mathrm{~ns}$ & $0.978 \mathrm{~ns}$ & $0.430 \mathrm{~ns}$ & $0.655 \mathrm{~ns}$ \\
\hline & $\mathrm{cv} \times \operatorname{trt}$ & 12 & $0.860 \mathrm{~ns}$ & $0.989 \mathrm{~ns}$ & $0.987 \mathrm{~ns}$ & $0.419 \mathrm{~ns}$ & $0.943 \mathrm{~ns}$ & $0.614 \mathrm{~ns}$ \\
\hline & cv x blk & 8 & $0.804 \mathrm{~ns}$ & $0.662 \mathrm{~ns}$ & $0.698 \mathrm{~ns}$ & $0.954 \mathrm{~ns}$ & $0.912 \mathrm{~ns}$ & $0.976 \mathrm{~ns}$ \\
\hline & trt $\mathrm{x}$ blk & 6 & $0.782 \mathrm{~ns}$ & $0.208 \mathrm{~ns}$ & $0.106 \mathrm{~ns}$ & $0.728 \mathrm{~ns}$ & $0.649 \mathrm{~ns}$ & $0.828 \mathrm{~ns}$ \\
\hline & cv $x$ trt $x$ blk & 24 & $0.755 \mathrm{~ns}$ & $0.321 \mathrm{~ns}$ & $0.384 \mathrm{~ns}$ & $0.452 \mathrm{~ns}$ & $0.230 \mathrm{~ns}$ & $0.527 \mathrm{~ns}$ \\
\hline
\end{tabular}

${ }^{\mathrm{a}} \mathrm{cv}=$ cultivar, trt $=$ treatment, blk $=$ block.

${ }^{\mathrm{b}}$ Veg $=$ vegetative biomass, Rep $=$ reproductive biomass, Rep:Tot $=$ reproductive effort, ratio of reproductive to total biomass.

${ }^{\mathrm{c}}$ Tot $=$ total number of axillary branches per plant, Flow = number of flowering axillary branches per plant, Flow:Tot $=$ reproductive allocation, ratio of number of flowering branches to total number of branches per plant.

$\mathrm{d} *, * * *, \mathrm{~ns}=$ significant, highly significant, and not significant to $\alpha=0.05$. 
A
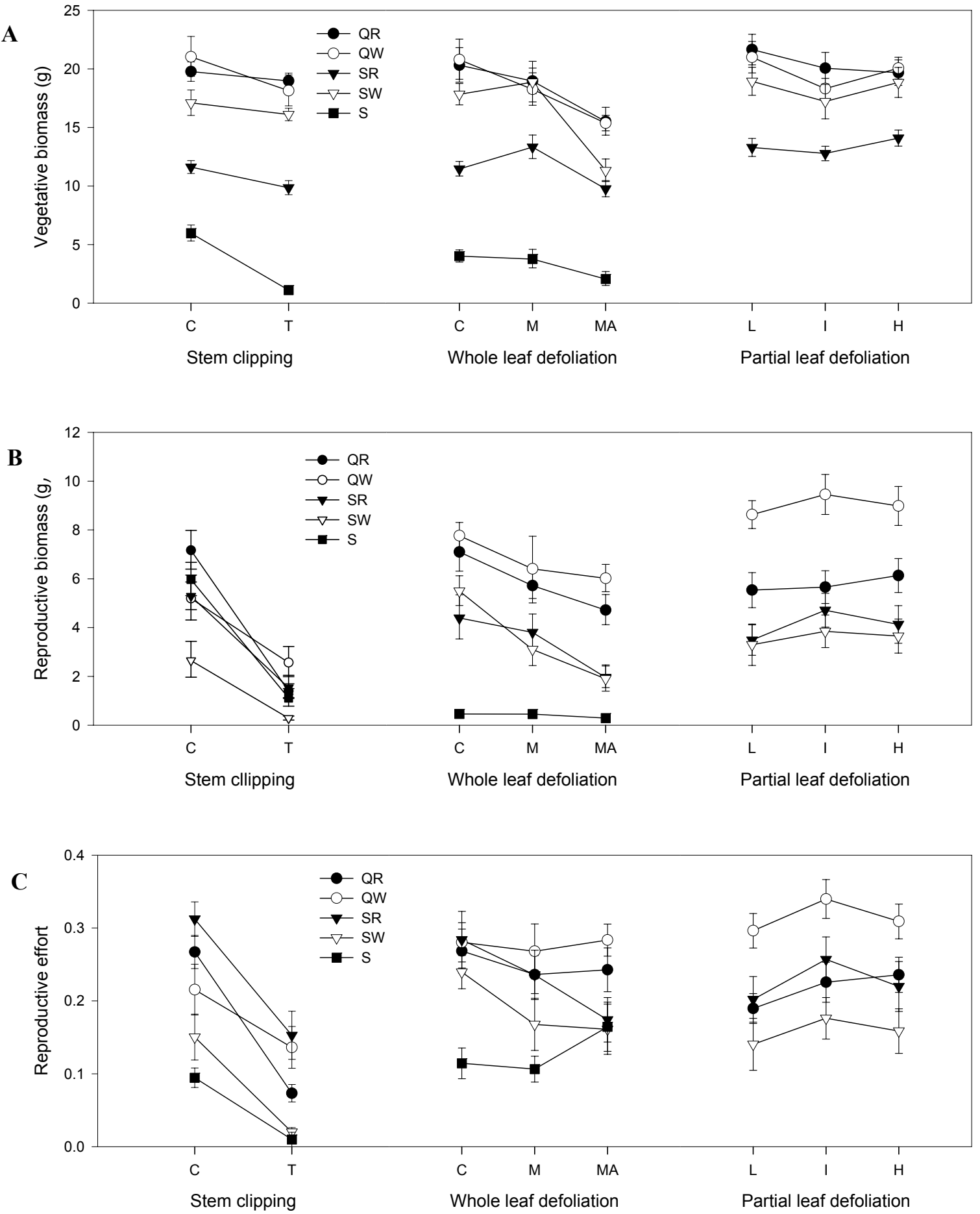

Figure 4. Mean $( \pm$ S.E. bars) biomass $(\mathrm{g})$ of $(\mathrm{A})$ vegetative and $(\mathrm{B})$ reproductive structures, $(\mathrm{C})$ reproductive effort (ratio of inflorescence biomass to total biomass) in Cleome cultivars (QR = Queen Rose, $\mathrm{QW}=\mathrm{Queen}$ White, $\mathrm{SR}=$ Sparkler Rose, $\mathrm{SW}=$ Sparkler White, $\mathrm{S}=\mathrm{Solo}$ ) in response to three simulated herbivory experiments (stem clipping, whole leaf defoliation, partial leaf defoliation). $\mathrm{C}=$ control, $\mathrm{T}=$ terminal half of the main stem clipped, $\mathrm{M}=$ main leaves removed, $\mathrm{MA}=$ both main and axillary leaves removed, $\mathrm{L}=$ low level damage $(20 \%$ of leaf area removed), $\mathrm{I}=$ intermediate level damage $(40-50 \%$ of leaf area removed), and $\mathrm{H}=$ high level damage $(80 \%$ of leaf area removed). S was excluded from the partial leaf defoliation experiment (See text) 
Reproductive effort, defined as the proportion of biomass allocated to inflorescences, averaged $21.0 \%$ (control) and $8.6 \%$ (treated) in the stem clipping experiment. A significant effect of herbivory $\mathrm{x}$ cultivar was not detected $(P=0.084$; Table 3$)$, suggesting a trend for cultivars to retain their relative ranks between the treatments. The overall tendency was a reduction in reproductive effort across all cultivars after stem clipping. Among control plants, SR allocated the most biomass to reproduction (31.7\%), followed by QR (27.0\%), QW (20.6\%), and SW (15.3\%) (Figure 4C). Among treated plants, the proportion allocated to reproductive effort was still high in SR $(15.8 \%)$ and low in SW (2.1\%), but QW (13.7\%) allocated more to reproduction than QR (7.4\%). S had the lowest reproductive effort with $10.0 \%$ biomass in control plants and only $4.2 \%$ in treated plants.

Total biomass in the whole defoliation experiment ranged from $2.3 \mathrm{~g}$ in S plants treated with the highest herbivory level to $28.5 \mathrm{~g}$ of control QW plants. QW and QR had the highest average total biomass across all treatments (24.5 g), followed by SW and SR (17.2 g) and S (3.7 g). Except for SR, the trend among cultivars was towards a decrease in total biomass as the intensity of herbivory increased. The average total biomass for control, intermediate, and high herbivory intensities was $19.9 \mathrm{~g}, 18.5 \mathrm{~g}$, and $13.8 \mathrm{~g}$, respectively. SR was the exception, producing the greatest biomass at the intermediate level of herbivory $(17.1 \mathrm{~g})$ rather than in the control $(15.9 \mathrm{~g})$ or highest level of herbivory treatment $(11.7 \mathrm{~g})$.

In the whole leaf defoliation experiment, vegetative biomass declined as the level of herbivory increased. The average vegetative biomass in control plants was $14.8 \mathrm{~g}$. At intermediate herbivory levels, it averaged $14.6 \mathrm{~g}$, whereas it significantly decreased to $10.8 \mathrm{~g}$ in plants at the highest herbivory level. The two exceptions to this trend were SR and SW, which had the highest vegetative biomass at intermediate levels of herbivory (Figure 4A).

The average reproductive biomass across all cultivars decreased from 5.0 to $3.9 \mathrm{~g}$ as whole leaf defoliation intensity increased. Unlike for total biomass and vegetative biomass, this trend was consistent among all cultivars. The relative ranks of cultivars in terms of their reproductive biomass is also similar to that observed for total biomass and vegetative biomass: QW and QR produced the most $(6.3 \mathrm{~g})$, followed by SW and SR $(3.4 \mathrm{~g})$ and S $(0.4 \mathrm{~g})$.

Average reproductive effort across all cultivars was highest for control plants $(23.7 \%)$ and lowest for the intermediate whole leaf defoliation level (20.2\%). Three distinct patterns of tolerance were observed among cultivars in terms of allocation of biomass to reproductive effort (Figure 4C). QR and QW showed no difference in reproductive effort across herbivory treatments, $24.9 \%$ and $27.7 \%$ biomass allocated to reproduction, respectively SR and SW showed a decrease in reproductive effort as the intensity of herbivory increased. In SR, there was $38.7 \%$ reduction in reproductive allocation in plants treated with the maximum herbivory intensity relative to the control group. In SW, the reduction was $32.7 \%$. However, in S there was a slight increase in reproductive allocation as herbivory intensity increased from $11.4 \%$ (control) to $16.4 \%$ in plants with both main and axillary leaves removed.

Total biomass in the partial leaf defoliation experiment ranged from $16.8 \mathrm{~g}$ in SR to $29.6 \mathrm{~g}$ in QW for the lowest intensity herbivory treatment. In general, there were no significant differences among treatments in total biomass produced. However, there was a slight increase in total biomass as intensity of treatment increase in SR. At $20 \%$ leaf area removal, total biomass was $16.8 \mathrm{~g}$. At $40 \%$ and $80 \%$ leaf area removal, there was an increase of $0.7 \mathrm{~g}$ and $1.4 \mathrm{~g}$, respectively. The other three cultivars showed a slight decrease in total biomass at intermediate levels of herbivory relative to the control group.

Like in the whole leaf defoliation experiment, no differences in vegetative and reproductive biomass were detected among partial leaf defoliation treatments. However, differences among cultivars were highly significant (Table 3). SR averaged the least vegetative biomass (13.4 g), followed by SW (18.3 g), QW (19.8 g) and QR (20.5 g) (Figure 4). In terms of reproductive biomass, SW produced the least (3.6 g), followed by SR (4.1 g), QR (5.8 g), and QW (9.0 g) (Figure 4B).

On average the highest reproductive effort in the partial leaf defoliation experiment was observed for the $40 \%$ leaf area removal treatment with an average of $20 \%$ biomass allocated to inflorescences across all cultivars (Figure 4), though significant treatment effects were not detected (Table 3). This suggests some degree of compensation at intermediate levels of herbivory. In addition, differences in reproductive effort across cultivars were highly significant (Table 3). SW allocated $15.8 \%$ of biomass to reproduction, whereas QW allocated $31.5 \%$.

\subsection{Shoots}

Stem clipped plants produced significantly fewer axillary shoots than control plants $(\mathrm{P}<0.001$, Table 3; Figure 5A). Among control plants, SW produced the highest number of axillary shoots per plant (13), while SR produced the least (7). Among treated plants, S produced the least number of axillary shoots per plant (two), while 
the highest number of shoots was produced by QW (six) instead of SW (four). The shift in relative ranking of cultivars depending on the treatment is denoted by the highly significant effect of the cultivar by treatment interaction $(P<0.001$, Table 3$)$.

A

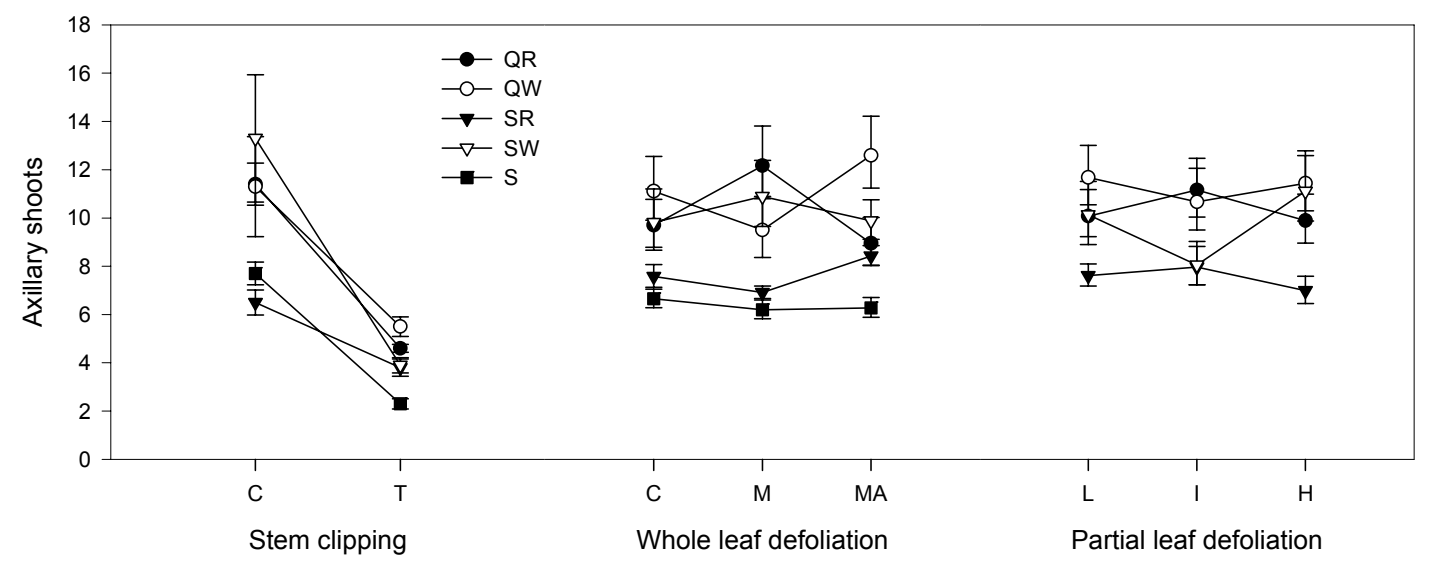

B

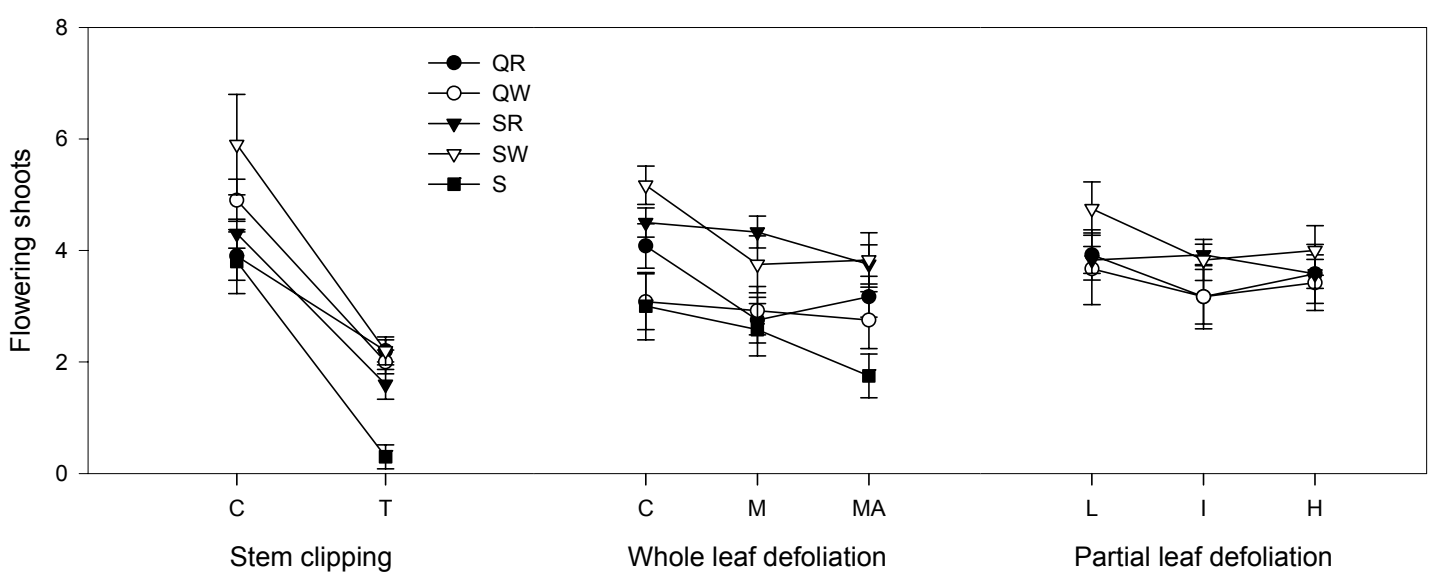

C

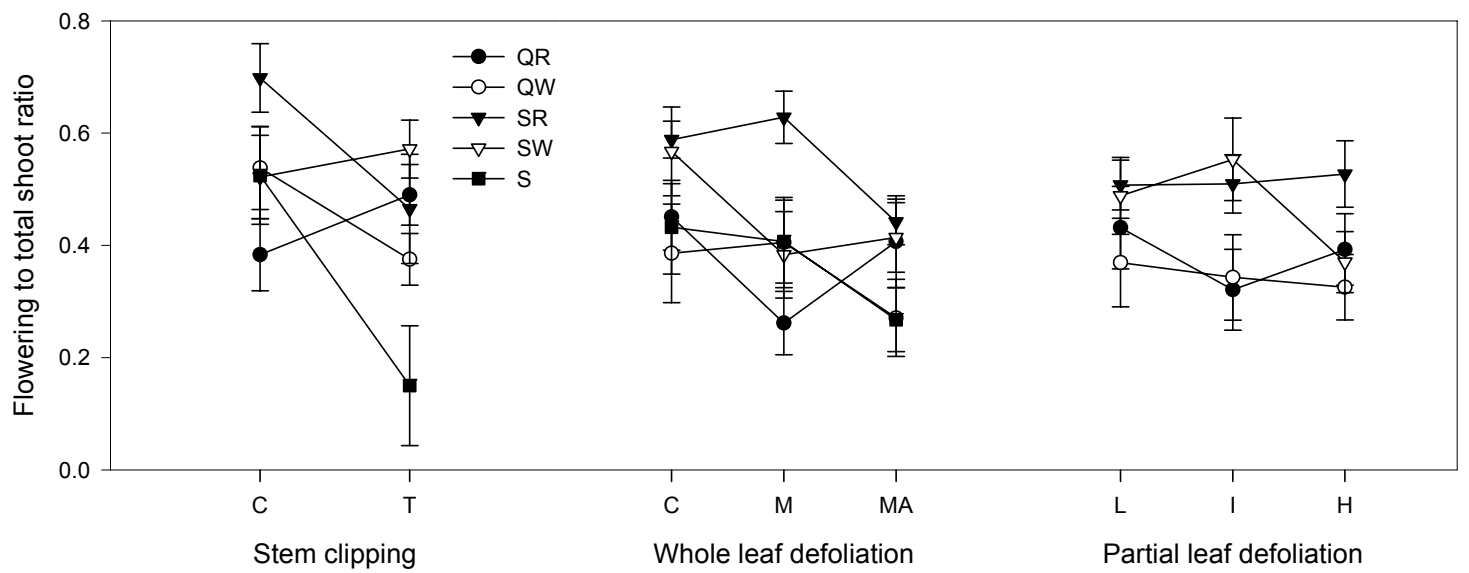

Figure 5. Mean ( \pm S.E. bars) number of (A) axillary shoots, (B) flowering shoots, and (C) reproductive allocation (ratio of flowering branches to total number of branches) in Cleome cultivars $(\mathrm{QR}=$ Queen Rose, $\mathrm{QW}=$ Queen White, $\mathrm{SR}=$ Sparkler Rose, $\mathrm{SW}=$ Sparkler White, $\mathrm{S}=$ Solo) in response to three simulated herbivory experiments (stem clipping, whole leaf defoliation and partial leaf defoliation). $\mathrm{C}=$ control, $\mathrm{T}=$ terminal half of the main stem clipped, $\mathrm{M}=$ main leaves removed, $\mathrm{MA}=$ both main and axillary leaves removed, $\mathrm{L}=$ low level damage $(20 \%$ of leaf area removed), $\mathrm{I}=$ intermediate level damage $(40-50 \%$ of leaf area removed), and $\mathrm{H}=$ high level damage $(80 \%$ of leaf area removed). $\mathrm{S}$ was excluded from the partial leaf defoliation experiment (See text) 
The number of flowering shoots in the control plants was more than twice the number of shoots in stem clipped plants (Figure 5B). No significant cultivar or interaction effects were detected for number of flowering shoots (Table 3). Among control plants, SW produced the most flowering shoots (six), followed by QW (five), and QR and SR (four). Among treated plants, all cultivars but S, produced, on average, two flowering shoots after herbivory.

Since stem clipping produced on average a reduction in total number of shoots without a significant change in the number of flowering shoots, there was a significant effect of treatment on reproductive allocation, the proportion of flowering shoots to total number of shoots per plant $(P=0.01$, Table 3$)$. A highly significant interaction of cultivar and herbivory in reproductive allocation $(P=0.009$; Table 3$)$ confirms that reaction norms vary significantly depending on cultivar and that the cultivars' relative ranks are not maintained across treatments (Figure 5C). Furthermore, reproductive allocation was greater in treated plants than control plants of QR and SW (Figure 5C). In the other three cultivars, treated plants had lower reproductive allocation percentages than control plants.

There was no significant difference in the number of total shoots/plant $(n=9)$ produced across whole leaf defoliation levels. No differences among all three levels of damage where observed in S and SW, producing an average across treatments of 6 and 10 shoots/plant, respectively (Figure 5A). In QR and SW the trend was an increase in total number of shoots in the intermediate levels of herbivory, whereas for QW and SR there was a slight decrease relative to control and the high intensity treatment.

The number of flowering shoots in the intermediate and high intensity whole leaf defoliation levels was less than in the control group (Figure 5B). The average number of flowering shoots in the control group was four flowering shoots/plant, whereas the average number of flowering shoots for the intermediate and high levels of herbivory were three shoots/plant. SR and SW produced the greatest number of flowering shoots among all cultivars $(\mathrm{n}=4)$, and $S$ produced the least $(n=2)$.

In terms of reproductive allocation, the ratio of flowering:total shoots, cultivars ranged from $48.5 \%$ in the control group to $36.0 \%$ in the maximum intensity in the whole leaf defoliation level. QW and S responded very similarly with the lowest ratio $(27.0 \%$ ) allocated to reproduction at the highest level of herbivory. Relative to the other cultivars, SR allocated more to reproductive shoots with an average of $55.3 \%$ flowering shoots across all treatments and the largest amount (62.8\%) allocated to reproduction in the intermediate herbivory level (Figure 5).

In the partial leaf defoliation experiment, no significant differences were detected among treatments in the total number of axillary shoots per plant, the number of flowering shoots and the proportion of flowering to total shoots (Table 3). Moreover, cultivar effects were not detected for number of flowering shoots per plant, but were significant for total number of shoots $(P<0.001)$ and the proportion of flowering shoots to total shoots $(P=0.01)$. Total number of shoots/plant ranged from 7 to 12 . The cultivar SR had the least mean number of total shoots $(\mathrm{n}=8)$, followed by SW and QR, each with 10 , and QW $(\mathrm{n}=11)$ (Figure 5A). Across all cultivars and treatments, the average number of flowering shoots $(\mathrm{n}=4)$. In terms of the proportion of flowering shoots to total shoots, SR and SW had a higher proportion (49.3\%) than QR and QW (36.4\%). There was a slight increase in the proportion of flowering shoots to total shoots in $\mathrm{SW}$, and a slight decrease in $\mathrm{QR}$, at the intermediate level of herbivory.

\subsection{Ovules}

Cultivars and treatment significantly affected the number of ovules produced per flower in the stem clipping experiment (Table 4). Control plants of QR, QW, and SR produced the most ovules $(n=87)$ per flower (Figure 6). The effect of herbivory was least on SR, which only experienced a $10 \%$ reduction in the number of ovules per flower compared to control plants. Treated S plants had a 52\% reduction, whereas QR and QW had an average of $41 \%$ reduction in ovule number. Missing counts of ovules for treated plants of SW are due to morphological abnormalities in the ovary. Morphological abnormalities in ovaries were significantly different across treatment $(\mathrm{P}<0.001)$, with a greater proportion of abnormalities in treated plants $(53 \%)$ versus control plants $(13 \%)$. However, no significant effect of cultivar was detected in the proportion of reproductive abnormalities $(P=0.144)$. 


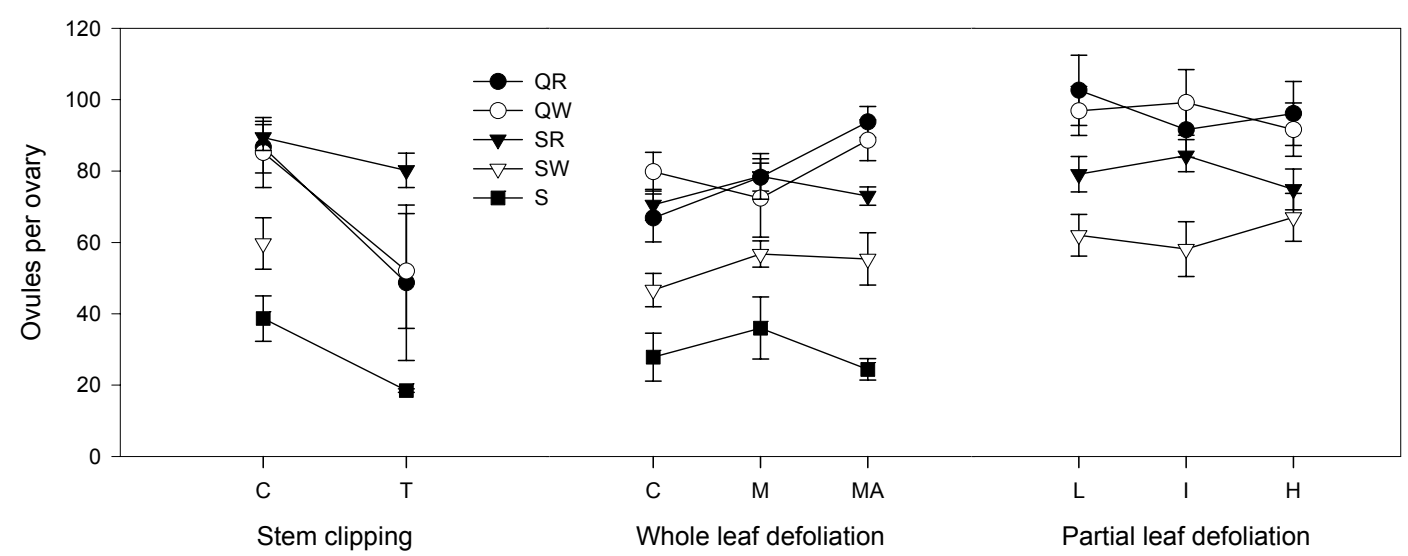

Figure 6. Mean ( \pm S.E. bars) number of ovules per flower of five Cleome cultivars $(\mathrm{QR}=$ Queen Rose, $\mathrm{QW}=$ Queen White, $\mathrm{SR}=$ Sparkler Rose, $\mathrm{SW}=$ Sparkler White, $\mathrm{S}=$ Solo) in response to three different simulated herbivory experiments (stem clipping, whole leaf defoliation, and partial leaf defoliation). $\mathrm{C}=$ control,

$\mathrm{T}=$ terminal half of the main stem clipped, $\mathrm{M}=$ main leaves removed, $\mathrm{MA}=$ main and axillary leaves removed,

$\mathrm{L}=$ low level damage ( $20 \%$ of leaf area removed), $\mathrm{I}=$ intermediate level damage (40-50\% of leaf area removed), and $\mathrm{H}=$ high level damage ( $80 \%$ of leaf area removed). 'Solo' was excluded from partial leaf defoliation experiment (See text)

On average, there was a suggestive trend towards number of ovules per flower increasing as the intensity of whole leaf defoliation increased $(P=0.084$, Table 4). The average number of ovules for the control plants was: 68 ovules/flower, 75 ovules/flower in plants with only the main leaves removed, and 78 ovules/flower in plants with both main and axillary leaves removed. The strongest case of overcompensation is observed in QR with a $40 \%$ increase of ovules per flower in the high intensity treatment relative to the control group (Figure 6). Nonetheless, this trend was not the same for all cultivars. QW and QR produced the most ovules per flower (94 and 93 ovules/flower, respectively). SR produced on average 86 ovules per flower, whereas SW produced 62 . S produced on average 34 ovules per flower.

Table 4. Significance ( $P$ values) from the analysis of variance for ovules and ovary lengths of five Cleome cultivars (Queen Rose, Queen White, Sparkler Rose, Sparkler White, and Solo) in response to three simulated herbivory experiments (stem clipping, whole leaf defoliation, and partial leaf defoliation)

\begin{tabular}{llll}
\hline Simulated herbivory & Factor $^{\mathrm{a}}$ & Ovules & Ovary length $^{\mathrm{b}}$ \\
\hline Stem clipping & ovlen $^{\mathrm{c}}$ & $<0.001^{* * *}$ & - \\
& $\mathrm{cv}$ & $0.003^{* * *}$ & $0.031^{*}$ \\
& trt & $<0.001^{* * *}$ & $0.804 \mathrm{~ns}$ \\
Whole leaf defoliation & $\mathrm{cv} \mathrm{x}$ trt & $0.024^{*}$ & $0.364 \mathrm{~ns}$ \\
& $\mathrm{ovlen}$ & $0.166 \mathrm{~ns}$ & - \\
& $\mathrm{cv}$ & $<0.001^{* * *}$ & $<0.001^{* * *}$ \\
& $\mathrm{trt}$ & $0.086 \mathrm{~ns}$ & $0.999 \mathrm{~ns}$ \\
Partial leaf defoliation & $\mathrm{cv} \mathrm{x}$ trt & $0.192 \mathrm{~ns}$ & $0.511 \mathrm{~ns}$ \\
& ovlen & $0.126 \mathrm{~ns}$ & - \\
& $\mathrm{cv}$ & $<0.001^{* * *}$ & $<0.001^{* * *}$ \\
& trt & $0.78 \mathrm{~ns}$ & $0.442 \mathrm{~ns}$ \\
& $\mathrm{cv} \mathrm{x} \mathrm{trt}$ & $0.861 \mathrm{~ns}$ & $0.282 \mathrm{~ns}$ \\
\hline
\end{tabular}

${ }^{\mathrm{a}}$ ovlen $=$ ovary length, $\mathrm{cv}=$ cultivar, trt $=$ treatment.

${ }^{\mathrm{b}}$ Ovary length as response variable, therefore no $P$ value available for ovary length.

$\mathrm{c} *, * * *, \mathrm{~ns}=$ significant, highly significant, and not significant to $\alpha=0.05$. 
As the intensity of partial leaf defoliation increased, there was a reduction in the number of ovules from 85 to 82 ovules/flower, though significance was not detected $(P=0.78$, data not shown). However, highly significant differences were detected among cultivars for the number of ovules per flower. SW produced the fewest ovules per flower $(\mathrm{n}=62)$, while $\mathrm{QR}$ produced the most $(\mathrm{n}=97)$ (Figure 6). There is no information available from SW treated plants because the ovaries collected were severely damaged by fungi, preventing ovule count.

\section{Discussion}

Cleome cultivars may exhibit varying degrees of tolerance, from undercompensation to overcompensation, in response to simulated herbivory and that there is variation in the response depending on the trait measured and the pattern of simulated herbivory. Compensatory ability in response to herbivory is a topic of substantial debate (Belsky, 1986; Cox, 2004). Some researchers state that most plant species exhibit reduced growth and fertility after herbivore attacks (Crawley, 1983) and evidence supporting compensation is lacking (Belsky, 1986). On the other hand, more recent studies in a wider range of species and environmental conditions suggest that, at least under certain conditions, species can increase their reproductive output after herbivory (Paige, 1999; Juenger, Lennartsson \& Tuomi, 2000; Stastny, Scharrner, \& Elle, 2005; Sun, Ding, \& Ren, 2009; Wise \& Abrahamson, 2005). In cleomes, compensatory ability varied among cultivars and pattern of herbivory.

Cleome cultivars exhibited variable degrees of tolerance across the experiments (Figures 3-6). For example, though complete recovery of removed biomass was not attained during the length of the stem clipping experiment, treated cultivars gained $>50 \%$ biomass by the end of the experiment suggesting a tendency to tolerate herbivory (Figure 4). Moreover, despite removal of up to $80 \%$ leaf area in the partial leaf defoliation, no treatment effects were detected in flowering phenology, biomass, shoot number or ovules/flower indicating compensation after herbivory in all these traits (Tables 2-5, Figures 3-6). These results are consistent with other studies that show compensation in invasive species. Schierenbeck, Mack, \& Sharitz (1994) found that, in the presence of herbivores, the alien species Lonicera japonica produced greater biomass than its native counterpart $L$. sempervirens. Rogers and Siemann (2004) reported that, unlike natives, invasive ecotypes of Chinese tallow tree (Sapium sebiferum) compensate for root damage. However, there are also studies that do not find differences in compensation by invasive and non-invasive species. For example, no differences in tolerance to herbivory were detected between American and European populations of Solidago canadensis (Van Kleunen \& Schmid, 2003).

Not only were highly significant differences among cultivars detected in most traits across all three herbivory experiments, but also more importantly, we observed variability among cultivars of the same series (Table 4). For example, SW produced greater vegetative biomass than SR after stem clipping and partial leaf defoliation and QR produced less reproductive biomass than QW in stem clipping and partial leaf defoliation experiments (Figure 4). In some instances, the difference between cultivars of the same series was greater than the difference between the series. For example, the proportion of biomass allocated to reproductive structures in clipped plants was greater in QW and SR than in QR and SW, whereas in the partial leaf defoliation experiment, QR allocated as much biomass to reproductive structures as SR and SW (Figure 4). Our results are consistent with previous findings that report variability in compensatory ability and invasive potential among closely related species. In a study of two closely related Conyza species, Thébaud et al. (1996) reported higher reproductive effort in Conyza canadensis than in C. sumatrensis, but stronger inflorescence stems and longer reproductive life-span in C. sumatrensis increased seed set in a wider range of environments. Gerlach and Rice (2003) observed that the greater invasive potential of Centaurea solstitialis relative to C. sulphurea and C. melitensis was due to this species' increase in the number of flower heads in response to stem clipping. These small physiological and morphological differences can result in large differences in invasiveness (Thébaud, Finzi, Affre, Debussche, \& Escarre, 1996; Gerlach \& Rice, 2003; Soti \& Volin, 2010).

Variation in tolerance to herbivory, as observed among Cleome cultivars, is expected because patterns of plant response to herbivory depend on heritable, morphological, species-specific characters (Li, Shibuya, Yogo, \& Hara, 2004). Genetic variation in tolerance to herbivory among natural populations has been documented in several species including Gentianella campestris (Juenger et al., 2000) and Ipomoea purpurea (Fineblum \& Rausher, 1995). It has also been documented for natural populations of invasive species Spartina alternifolia (Garcia-Rossi, Rank, \& Strong, 2003) and Alliaria petiolata (Bossdorf et al., 2004). Nonetheless, genetic variation in herbivore tolerance is often ignored in development of invasive species control. For example, the variation in tolerance and palatability of invasive species can have significant implications for the effectiveness of biological control agents (Bossdorf et al., 2004). This is because highly tolerant species can support large populations of biological control agents without a negative impact in their population size (Müller-Schärer et al., 2004; Garcia-Rossi et al., 2003). 
In addition to genetic variation among populations, differing patterns of herbivory in Cleome can result in completely different responses (Figures 2-6). Herbivore treatment effects were significant for most of the traits in the stem clipping and whole leaf defoliation experiments, but treatment effects were not detected in the partial leaf defoliation experiment (Table 3). The most dramatic and negative effect was observed on reproductive biomass in the stem clipping experiment resulting in undercompensation with less biomass allocated to reproduction in treated plants than in controls (Figure 4). The decline in biomass is less dramatic in the whole leaf defoliation experiment than in the stem clipping experiment. In the whole leaf defoliation experiment, for example, treated $\mathrm{S}$ plants produced as much biomass as controls, whereas those in the stem clipping experiment had significantly less biomass (Figure 4). The least effect on biomass was observed in plants in the partial leaf defoliation experiment. In this experiment, there was no detectable treatment effect across variables measured, though there was a trend towards overcompensation through an increase in biomass allocated to reproduction. Similar trends were observed in the number of flowering shoots/plant where stem clipping had more dramatic and detrimental effects than whole leaf and partial leaf defoliation experiments (Figure 5).

Differences in response to various patterns of herbivory treatment were consistent with findings from other studies. In a simulated herbivory experiment on Alliaria petiolata, apical meristem damage and leaf herbivory (folivory) result in different magnitudes of growth and reproduction response (Bossdorf et al., 2004). Moreover, a combination of herbivore treatments may be necessary to describe more accurately the response to herbivory of a species in a new range. For example, in Solidago canadensis, a combination of clipping and jasmonic acid treatments better simulates natural response to herbivory damage than either treatment alone (van Kleunen, Ramponi, \& Schmid, 2004). In Lonicera japonica, maximum compensation occurred only after exposure to herbivory by both insects and mammals (Schierenbeck et al., 1994).

Cultivar $\mathrm{x}$ treatment interactions were more striking in the stem clipping experiment than in the whole leaf defoliation experiments and no significant interaction was detected in the partial leaf defoliation experiment (Table 3). In the stem clipping experiment, total biomass allocated to reproduction was less in treated plants (Figure 4), but the effect of treatment varied across cultivars being greatest in $\mathrm{S}$ and less severe in QW. In the same experiment, QR and SR overcompensated by producing a greater proportion of flowering shoots compared to controls (Figure 5). This could be the result of short axillary shoots producing flowers sooner in QR and SR than in the other cultivars. If the shoots contributing to the proportion of flowering : total number of shoots are small enough, they may be of significant impact on fitness despite contributing little to total reproductive biomass. In the whole leaf defoliation experiment, there were trends suggesting differences among cultivars in the magnitude of the herbivory effect. For example, there was a greater decline in the biomass allocated to reproduction in SR and SW than in QR and QW, but an increase in S (Figure 4). There was also a slight increase in the vegetative biomass of SR and SW treated with the low intensity relative to the high intensity level of whole leaf defoliation, but this pattern was not observed in QW, QR or S. An interaction between cultivars x herbivory treatments was less detectable in the partial leaf defoliation experiment where vegetative and reproductive biomass varied little across treatments. Interestingly, plants tended to increase biomass allocation to reproduction with herbivory; QW, SR and SW maxed at intermediate levels of herbivory, whereas QR maxed at high levels of herbivory (Figure 4).

Cultivar and herbivory also affected the number of ovules produced/flower (Table 4). Even after including ovary length in the statistical model, strong cultivar effects on the number of ovules/ovary were detected across all experiments. Herbivory effects on ovule counts were highly significant in the stem clipping experiment, marginally significant in the whole leaf defoliation experiment, and non-significant in the partial leaf defoliation experiment suggesting a range of tolerance from undercompensation to compensation. Clipped plants produced significantly fewer ovules/flower than controls, but the magnitude of the effect differed significantly across cultivars; treated SR plants produced as many ovules per ovary as controls, whereas QR, QW and S produced fewer ovules in treated plants (Figure 6). Cultivar by herbivory effects were non-significant in the whole leaf and partial leaf defoliation experiments, but a trend towards overcompensation through an increase in number of ovules/flower was detected in plants in the whole leaf defoliation experiment especially in QR. These results contrast with studies that focus specifically on male and female fitness components. For example, studies in Ipomopsisaggregata have detected overcompensation in total fitness when estimates of the effect of herbivory include male fitness components (Gronemeyer, Dilger, Bouzat, \& Page, 1997), but they have not detected overcompensation in female fitness components of total fruit or seed set (Paige, 1999). In a different species, Ipomopsis arizonica, reproductive success after herbivory was due solely to male fitness component instead of female fitness components (Paige, Williams, \& Hickox, 2001). 


\section{Conclusion}

Reallocation of resources to growth or reproduction after herbivory can be advantageous for species colonizing new areas (Blundell \& Peart, 2001; Erneberg, 1999; Rogers \& Siemann, 2004; Sun et al., 2009). However, establishing the connection between response to herbivory and invasive potential is extremely difficult. In some cases, herbivory can be a strong barrier limiting plant invasions (Lambrinos, 2002; D'Antonio, 1993), but in other cases it may have minor impact on plant establishment (Thébaud et al., 1996). Moreover, herbivory is highly variable across year and environments, and greatly dependent on community type (Lambrinos, 2002; Thébaud et al., 1996). Many factors including deer paths, weather conditions and the availability of other plants will determine whether Cleome is attacked by herbivores (City of Lakeway, TX, 2005). Therefore, protocols to assess invasive potential of ornamental crops in terms of tolerance to herbivory should start with pilot studies that compare simulated and natural herbivory patterns, determine the most important traits associated with tolerance, and correlate greenhouse with field response to herbivory.

Development of adequate protocols to evaluate the invasive potential of ornamental crops before market is advisable because various patterns of herbivory may result in different responses. It is expected that feeding modes of different herbivores will determine which traits are most important in determining tolerance to herbivory (Strauss \& Agrawal, 1999). Further experiments with these species could focus on changes in chemical (defense compounds) and morphological barriers to herbivory (plant pubescence, spines). Experiments designed to assess tolerance to herbivory in cultivars developed by ornamental breeding programs may need to include different patterns of simulated and natural herbivory (Tiffin \& Inouye, 2000; Lehtilä, 2003; Inouye \& Tiffin, 2003) to provide thorough information on how cultivars respond to different types of herbivores encountered in natural conditions. Though simulated experiments are practical (Hjältén, 2004), especially in the context of breeding programs trying to evaluate invasive potential of ornamental crops, natural herbivory experiments may be needed to understand the complex ecological processes and biotic interactions leading to species invasions.

The difference in tolerance observed among cleome cultivars of the same series and species suggest the importance of evaluating each cultivar independently to assess its response to herbivory. In general, cultivars within a series are expected to share similar phenotypes except for flower color. This study shows that this assumption deserves re-examination for invasive potential because cultivars within a series are not genetically homogeneous. It may be necessary to evaluate all cultivars within the series to determine whether an entire series could be marketed as less invasive than another.

In addition to the different effects caused by type of herbivory and cultivars, the ability to detect tolerance to herbivory and compensation is determined by other factors including the traits examined and the conditions in which plants are grown. We focused on biomass allocation, branching and ovule production in our study, but other traits, such as time to flowering, fruit and seed production, and paternal fitness could be studied to determine more thoroughly how cleomes respond to herbivory. We also performed our studies in the greenhouse with sufficient lighting, nutrients, water and minimal competition among plants. All these factors may have an effect on the levels of tolerance observed in our study because resource levels can also affect tolerance to herbivory (Wise \& Abrahamson, 2005). Moreover, rapid evolutionary change in tolerance to herbivores in species undergoing range expansion (Müller-Schärer et al., 2004) will surely complicate our ability to predict which cultivars could become invasive.

To the best of our knowledge, this is the first study that focuses on the differences in tolerance to herbivory of cultivars of a commercial ornamental crop prior to naturalization with reference to potential implications for plant breeding programs and the efforts to minimize the distribution of invasive species of ornamental origin. Our study documents variation in tolerance to herbivory among cultivars and shows that compensatory ability varies with type of herbivory and the cultivar affected. This variation could be further explored in plant breeding programs that aim to develop species with reduced invasive potential, but much more research would be needed to directly correlate the impact of compensation on invasive potential. Development and implementation of protocols to evaluate invasive potential of crops, including tolerance to herbivory, before marketing a cultivar as less invasive could be advantageous to controlling invasive species of ornamental value.

\section{Acknowledgments}

This manuscript publication is Scientific Journal Series No. 0612190163 of the Department of Horticultural Science, University of Minnesota; research was funded by the Minnesota Agricultural Experiment Station. The authors thank Tami Van Gaal at Wagner's Greenhouse, Minneapolis, Minnesota for technical assistance. 


\section{References}

Bailey, L. H. (1927). The standard cyclopedia of horticulture (Vol. 1: A-E). New York, NY: The Macmillan Company.

Ball, V. (1965). The Ball red book (11th ed.). Batavia, Illinois: Ball Publishing.

Belsky, A. J. (1986). Does herbivory benefit plants? A review of the evidence. Amer. Nat., 127, 870-892. http://dx.doi.org/10.1086/284531

Bergquist, J., Bergstrom, R., \& Zakharenka, A. (2003). Responses of young Norway spruce (Piceaabies) to winter browsing by roe deer (Capreoluscapreolus): Effects on height growth and stem morphology. Scand. J. Forest Res., 18, 368-376. http://dx.doi.org/10.1080/0282758031005431

Bigger, D. S., \& Marvier, M. A. (1989). How different would a world without herbivory be? A search for generality in ecology.Integrative Biol., 1, 60-67. http://dx.doi.org/10.1002/(SICI)1520-6602(1998) 1:2\%3C60::AID-INBI4\%3E3.0.CO;2-Z

Blossey, B., \& Nötzold, R. (1995). Evolution of increased competitive ability in invasive nonindigenous plants: a hypothesis. J. Ecol., 83, 887-889. http://dx.doi.org/10.2307/2261425

Blundell, A. G., \& Peart, D. R. (2001). Growth strategies of a shade-tolerant tropical tree: the interactive effect of canopy gaps and simulated herbivory. J. Ecol., 89, 608-615. http://dx.doi.org/10.1046/ j.0022-0477.2001.00581.x

Bossdorf, O., Schröder, S., Prati, D., \& Harald, A. (2004). Palatability and tolerance to simulated herbivory in native and introduced populations of Alliariapetiolata (Brassicaceae). Amer. J. Botany, 91, 856-862. http://dx.doi.org/10.3732/ajb.91.6.856

Chamberlain, C. J. (1932). Methods in plant histology (5th Rev. ed.). Chicago, Illinois: The University of Chicago Press.

City of Lakeway, TX. (2005). Deer resistant plants; Public communications. Retrieved from http://cityoflakeway. com/about.asp

Crawley, M. J. (1983). Herbivory. The dynamics of animal plant interactions. Oxford: Blackwell. http://dx.doi.org/10.1146/annurev.en.34.010189.002531

Crawley, M. J. (1989). Insect herbivores and plant population dynamics.Ann. Rev. Entomology, 34, 531-564.

Cronquist, A. (1988). The evolution and classification of flowering plants (2nd ed.). Brooklyn: New York Botanical Garden.

D’Antonio, C. M. (1993). Mechanisms controlling invasion of coastal plant communities by the alien succulent Carpobrotusedulis. Ecol., 74, 83-95. http://dx.doi.org/10.2307/1939503

de Mazancourt, C., Loreau, M., \& Dieckmann, U. (2001). Can the evolution of plant defense lead to plant-herbivore mutualism? Amer. Naturalist, 158, 109-123. http://dx.doi.org/10.1086/321306

Erneberg, M. (1999). Effects of herbivory and competition on an introduced plant in decline. Oecologia, 118, 203-209. http://dx.doi.org/10.1007/s004420050719

Garcia-Rossi, D., Rank, N., \& Strong, D. R. (2003). Potential for self-defeating biological control?Variation in herbivore vulnerability among invasive Spartina genotypes. Ecol. Appl., 13, 1640-1649. http://dx.doi.org/10.1890/01-5301

Gerlach, J. D., \& Rice, K. J. (2003). Testing life history correlates of invasiveness using congeneric plant species. Ecol. Appl., 13, 167-179. http://dx.doi.org/10.1890/1051-0761(2003)013\%5B0167:TLHCOI\%5D2.0.CO;2

Gleason, H. A., \& Cronquist, A. (1991). Manual of vascular plants of northeastern United States and adjacent Canada (2nd ed.). Brooklyn: New York Botanical Garden.

Gronemeyer, P. A., Dilger, B. J., Bouzat, J. L., \& Paige, K. N. (1997). The effects of herbivory on paternal fitness in scarlet gilia: better moms also make better pops. Amer. Naturalist, 150, 592-602. http://dx.doi.org/10.1086/286083

Hester, A. J., Millard, P., Baillie, G. J., \& Wendler, R. (2004). How does the timing of browsing affect above- and below-ground growth of Betulapendula, Pinussylvestris and Sorbusaucuparia? Oikos, 105, 536-550. http://dx.doi.org/10.1111/j.0030-1299.2004.12605.x 
Hjältén, J. (2004). Simulating herbivory: problems and possibilities. Ecol. Studies, 173, 243-255. http://dx.doi.org/10.1007/978-3-540-74004-9_12

Hochwender, C. G., Marquis, R. J., \&Stowe, K. A. (2000). The potential for and constraints on the evolution of compensatory ability in Asclepias syriaca. Oecologia, 122, 361-370. http://dx.doi.org/10.1007/s00442005 0042

Inouye, B. D., \& Tiffin, P. (2003). Measuring tolerance to herbivory with natural or imposed damage: a reply to Lehtilä. Evolution, 57, 681-682.

JMP IN. (1989-2000). Version 4. Cary, North Carolina: SAS Institute, Inc.

Joshi, J., \& Vrieling, K. (2005). The enemy release and EICA hypothesis revisited: incorporating the fundamental difference between specialist and generalist herbivores. Ecol. Letters, 8, 704-714. http://dx.doi.org/10.1111/ j.1461-0248.2005.00769.x

Juenger, T., Lennartsson, T., \& Tuomi, J. (2000). The evolution of tolerance to damage in Gentianellacampestris: natural selection and the qualitative genetics of tolerance. Evol. Ecol., 14, 393-419. http://dx.doi.org/10.1023/ A:1010908800609

Keane, R. M., \& Crawley, M. J. (2002). Exotic plant invasions and the enemy release hypothesis. Trends in Ecol. and Evol., 17, 164-170. http://dx.doi.org/10.1016/S0169-5347(02)02499-0

Kindscher, K. (1987). Edible wild plants of the prairie: An ethnobotanicalguide. Lawrence, Kansas: University Press of Kansas.

Lambrinos, J. G. (2002). The variable invasive success of Cortaderia species in a complex landscape. Ecol., 83, 518-529. http://dx.doi.org/10.1890/0012-9658(2002)083\%5B0518:TVISOC\%5D2.0.CO;2

Li, B., Shibuya, T., Yogo, Y., \& Hara, T. (2004). Effects of ramet clipping and nutrient availability on growth and biomass allocation of yellow nutsedge. Ecol. Res., 19, 603-612. http://dx.doi.org/10.1111/j.1440-1703.2004. 00685.x

Markkola, A., Kuikka, K., Rautio, P., Härmä, E., Roitto, M., \& Tuomi, J. (2004). Defoliation increases carbon limitation in ectomycorrhizal symbiosis of Betulapubescens. Oecologia, 140, 234-240. http://dx.doi.org/10. 1007/s00442-004-1587-2

Müller-Schärer, H., Schaffner, U., \& Steinger, T. (2004). Evolution in invasive plants: implications for biological control. Trends in Ecol. and Evol., 19, 417-422. http://dx.doi.org/10.1016/j.tree.2004.05.010

Nau, J. (1999). Ball culture guide.The encyclopedia of seed germination (3rd ed.). Batavia, Illinois: Ball Publishing.

Paige, K. (1999). Regrowth following ungulate herbivory in Ipomopsisaggregata: geographic evidence for overcompensation. Oecologia, 118, 316-323. http://dx.doi.org/10.1007/s004420050732

Paige, K., Williams, B., \& Hickox, T. (2001). Overcompensation through the paternal component of fitness in Ipomopsisarizonica. Oecologia, 128, 72-76. http://dx.doi.org/10.1007/s004420100647

Reichard, S. H., \& White, P. (2001).Horticulture as a pathway of invasive plant introductions in the United States.BioScience, 51, 103-113. http://dx.doi.org/10.1641/0006-3568(2001)051\%5B0103:HAAPOI\%5D2.0. $\mathrm{CO} ; 2$

Rogers, W. E., \& Siemann, E. (2003). Effects of simulated herbivory and resources on Chinese tallow tree (Sapiumsebiferum, Euphorbiaceae) invasive of native coastal prairie.Amer. J. Bot., 90, 243-249. http://dx.doi.org/10.3732/ajb.90.2.243

Rogers, W. E., \& Siemann, E. (2004). Invasive ecotypes tolerate herbivory more effectively than native ecotypes of the Chinese tallow tree. Sapiumsebiferum. J. Appl. Ecol., 41, 561-570. http://dx.doi.org/10.1111/j.00218901.2004.00914.x

Schierenbeck, K. A., Mack, R., \& Sharitz, R. R. (1994). Effects of herbivory on growth and biomass allocation in native and introduced species of Lonicera.Ecology, 75, 1661-1672. http://dx.doi.org/10.2307/1939626

Soti, P. G., \& Volin, J. C. (2010). Does water hyacinth (Eichhorniacrassipes) compensate for simulated defoliation? Implications for effective biocontrol. Biol. Control, 54, 35-40. http://dx.doi.org/10.1016 j.biocontrol.2010.01.008

SPSS Inc. (2001). SPSS for Windows.Version 11. Chicago, Ilinois: SPSS Inc. 
Stastny, M., Schaffner, U., \& Elle, E. (2005). Do vigour of introduced populations and escape from specialist herbivores contribute to invasiveness? J. Ecol., 93, 27-37. http://dx.doi.org/10.1111/j.1365-2745. 2004.00962.x

Steffey, J. (1984). Strange relatives: The Caper family. Amer. Horticulturalist, 63, 4-7.

Still, S. (1994). Manual of herbaceous ornamental plants (4th ed.). Champaign, Illinois: Stipes Publishing Company.

Strauss, S. Y., \& Agrawal, A. A. (1999). The ecology and evolution of plant tolerance to herbivory. Trends in Ecol. and Evol., 14, 179-185. http://dx.doi.org/10.1016/S0169-5347(98)01576-6

Sun, Y., Ding, J., \& Ren, M. (2009). Effects of simulated herbivory and resource availability on the invasive plant, Alternantheraphiloxeroides in different habitats. Biol. Control, 48, 287-293. http://dx.doi.org/10.1016/ j.biocontrol.2008.12.002

Thébaud, C., Finzi, A. C., Affre, L., Debussche, M., \& Escarre, J. (1996). Assessing why two introduced Conyza differ in their ability to invade Mediterranean old fields. Ecol., 77, 791-804. http://dx.doi.org/10.2307/2265502

Tiffin, P., \& Inouye, B. D. (2000). Measuring tolerance to herbivory: accuracy and precision of estimates made using natural versus imposed damage. Evol., 54, 1024-1029. http://dx.doi.org/10.1111/j.0014-3820.2000. tb00101.x

Tiffin, P., \& Rausher, M. D. (1999). Genetic constraints and selection acting on tolerance to herbivory in the common morning glory, Ipomoea purpurea. Amer. Naturalist, 154, 700-716. http://dx.doi.org/10.1086/ 303271

U.S. Department of Agriculture.Plants Database. (2005). Cleome hassleriana. Retrieved from http://plants.usda.gov/

vanKleunen, M., \& Schmid, B. (2003). No evidence for an evolutionary increased competitive ability in an invasive plant. Ecol., 84, 2816-2823. http://dx.doi.org/10.1890/02-0494

vanKleunen, M., Ramponi, G., \& Schmid, B. (2004). Effects of herbivory simulated by clipping and jasmonic acid on Solidago canadensis. Basic and Appl. Ecol., 5, 173-181. http://dx.doi.org/10.1078/1439-1791-00225

Whitson, T. D. (Ed). (1991). Weeds of the west. Las Cruces, New Mexico: The Western Society of Weed Science in Cooperation with the Western United States Land Grant Universities.

Wise, M. J., \& Abrahamson W. G. (2005). Beyond the compensatory continuum: environmental resource levels and plant tolerance of herbivory. Oikos, 109, 417-428. http://dx.doi.org/10.1111/j.0030-1299.2005.13878.x

\section{Copyrights}

Copyright for this article is retained by the author(s), with first publication rights granted to the journal.

This is an open-access article distributed under the terms and conditions of the Creative Commons Attribution license (http://creativecommons.org/licenses/by/3.0/). 